\title{
Compositional Description of Three-Phase Flow Model in a Gas-Lifted Well with High Water-Cut
}

\author{
M. Mahmudi and M. Taghi Sadeghi* \\ Process Simulation and Control Research Lab., Department of Chemical Engineering, University of Science and Technology (IUST), \\ Narmak 16844, Tehran - Iran \\ e-mail: mahmudi@iust.ac.ir - sadeghi@iust.ac.ir \\ * Corresponding author
}

\begin{abstract}
Résumé - Description de la composition des trois phases du modèle de flux dans un puits utilisant la poussée de gaz avec des proportions d'eau élevées - La technique par poussée de gaz dite gas-lift fait partie des solutions durables de production à long terme des champs pétroliers. Pour un champ pétrolier en opération affecté par des proportions d'eau élevées, un modèle de composition en trois phases, décrivant le procédé continu de gas-lift, a été développé. Les données du champ pétrolier pour différentes proportions d'eau ont été évaluées pour pouvoir comparer le modèle black-oil en trois phases avec un modèle compositionnel. Lorsque les proportions d'eau augmentent, les résultats montrent qu'une déviation conséquente peut avoir lieu lorsque la méthode compositionnelle est utilisée en comparaison avec le modèle black-oil. En raison des différentes propriétés du gaz d'injection et du gaz produit dans les séparateurs, le traitement compositionnel serait a priori nécessaire pour modéliser le procédé de gas-lift. De plus, les calculs portant sur un équilibre en trois phases pour les mélanges d'hydrocarbures et d'eau dans le gas-lift du puits, sont nécessaires pour des proportions d'eau modérées et élevées.
\end{abstract}

Abstract - Compositional Description of Three-Phase Flow Model in a Gas-Lifted Well with High
Water-Cut - Gas-lift technique is part of a long-term production sustainability solution in oil fields
amid increasing water cuts and depleting reservoir energy. A three-phase compositional model
describing the continuous gas-lift process for an operational oilfield experiencing high water-cut is
developed. Field data with different water-cut values was considered to compare a three-phase black-oil
model against its compositional counterpart. Results show that significant deviation may encounter when
compositional method is employed in contrast to the black-oil model as water-cut increases. Due to
different properties of the injection gas and produced gas in separators, the compositional treatment
would be necessary for modeling the gas-lift process. Moreover, three-phase equilibrium calculations for
hydrocarbon-water flow mixtures in the gas-lifted well with moderate and high water-cut are required. 


\section{List of symbols}

$f_{i} \quad$ Fugacity of component $i$

$K$ Equilibrium constant

$N_{c}$ Number of components

$P \quad$ Pressure (bar)

$x_{i} \quad$ Mole fraction of component $i$ in liquid phase

$y_{i} \quad$ Mole fraction of component $i$ in vapor phase

$z$ Feed composition

$O$ Hydrocarbon-rich liquid phase fraction

$V$ Vapor phase fraction

$V s$ Superficial velocity $(\mathrm{m} / \mathrm{s})$

$W$ Water-rich liquid phase fraction

$\emptyset_{i} \quad$ Fugacity coefficient of component $i$

\section{Superscripts}

$O$ Hydrocarbon-rich phase indicator

$V$ Vapor phase indicator

$W$ Water-rich phase indicator

\section{INTRODUCTION}

One of the most important issues in oil fields is a high water production that may lead to well killing and reduction of oil production rate. The continuous gas-lift process is widely used to improve the production from these oil fields. In this process, high-pressure natural gas is injected into the wellbore to lighten the column of fluid allowing the reservoir pressure to force the fluid to the surface [1]. The fluids in gas-lift process consist of different components including hydrocarbons and water distributed in three phases (waterrich liquid, hydrocarbon-rich liquid and vapor). The accuracy and speed of computation for the continuous gas-lift model depend directly on the complexity of the thermodynamic description of the fluids involved. Most studies such as Guanren [2], Shi et al. [3], Cazarez-Candiaa and VasquezCruz [4] and Hasan et al. [5] performed hydrocarbon-water system calculations based on the simplified black-oil equations. The basic assumption in the black-oil approach is to consider hydrocarbon-water fluids as three pseudo-components namely oil, gas and water. The black-oil model assumes that no mass transfer occurs between the water phase and the other two phases. Moreover, only two components are considered in the hydrocarbon system. The oil component (stock-tank oil) refers to the residual liquid at atmospheric pressure left after differential vaporization, while the gas component is the remaining fluid [6]. In the black-oil model, the gas can be dissolved in the oil phase. A three-phase black-oil model usually treats PVT properties of hydrocarbon-water phases as a mere function of pressure and temperature. Hence, oil, gas and water properties are computed by experimental correlations at each pressure and temperature. The effect of the compositions on pressure and temperature changes is neglected in the black-oil approach.

The main question in using black-oil approach is its validity. In fact, the effect of the compositions on pressure profile and fluid flow properties should be taken into account when the flowing liquid and gas are composed of more than one component. The wise approach to predict the phase behavior is a compositional description in which all components are allowed to distribute between the phases. The most common way was to perform a two-phase equilibrium calculation combined with a steam table instead of a real three-phase equilibrium calculation [7, 8]. Essentially, the equilibrium calculation is performed first without water to get phase distribution and compositions for the hydrocarbon-rich phase as well as the vapor phase. Next, water is taken into account using a steam table; this approach is fast but not consistent, since adding water breaks equilibrium and may result in over or underestimation of evaporation or condensation [9]. The development of compositional modeling with equation of state formulations has received an increasing attention in recent years [10]. Such formulations require three-phase flash calculations in each time step. Iranshahr et al. [11] presented a three-phase flash method admitting an additional assumption, in which the solubility of water in the hydrocarbon-rich liquid phase is neglected. Recently, Lapene et al. [9] presented a free-water flash method that assumes the solubility of hydrocarbon components in the water-rich liquid phase is negligible, which means this phase consists of pure water.

In this paper, we present a three-phase compositional gaslift model based on the free-water flash algorithm proposed by Lapene et al. [9] to model a gas-lift process with high water-cut. A real field data case study with different watercut value is modeled based on the compositional model. Results are compared with a three-phase black-oil model showing how the compositional approach is important and when the black-oil approximation model is accurate.

\section{PRESSURE DROP CALCULATION}

Pressure drop in the gas-lifted well can lead to a loss of oil production at the toe or overproduction at the heel. In order to model the gas-lift process, accurate well flow models must be incorporated into reservoir model. In the gas-lift process, the gas injection leads to more flow pattern variety through the well. Within the context of petroleum engineering, two types of two-phase flow models most commonly used are empirical correlations and mechanistic models. The empirical correlations can yield good results but only limited to the same conditions as the experiments. Furthermore, many empirical flow maps exhibit large discontinuities at the flow pattern transitions and this can cause convergence problems 
in pressure gradient integration through the well. Compared to empirical correlations, the mechanistic modeling approach is more rigorous and has the potential of providing more reliable predictions of liquid hold-up and pressure gradients for gas and liquid flow in the wells. Mechanistic flow maps are developed from the analysis of physical mechanisms, which are produced by fundamental mass and momentum balance equations. In mechanistic models, the effects of system parameters are incorporated. Therefore, they can be applied over a range of geometry and fluid conditions. For most of the observed flow patterns, one or more empirical closure relationships are required. In this study, a mechanistic flow map and correlations based on the solution of the mass and momentum equations developed by Petalas and Aziz [12] was employed to predict flow regimes and pressure gradient in the gas-lifted well. The procedure of Petalas and Aziz [12] mechanistic model for flow pattern determination begins with the assumption that a particular flow pattern exists and is followed by an examination of the various criteria that establish the stability of the flow regime. If the regime is shown to be unstable, a new flow pattern is assumed and the procedure is repeated. The procedure for flow pattern determination is illustrated in Figure 1. It can be seen that the examination of the dispersed bubble flow regime is the first to be considered.

\subsection{Dispersed Bubble Flow}

The dispersed bubble flow region is bounded by two criteria. The first is based on the transition to slug flow where a transition from intermittent flow occurs when the liquid fraction in the slug is less than the value associated with the maximum volumetric packing density of the dispersed bubbles (0.52). A transition from dispersed bubble flow to froth flow can also occur when the maximum volumetric packing density of the dispersed gas bubbles is exceeded. If these two criteria are not satisfied, dispersed bubble flow is not possible and the possibility of stratified flow is examined next.

\subsection{Stratified Flow}

The present model limits stratified flow to horizontal and downhill angles only. This approach is also supported by the fact that stratified flow is only observed for small upward angles in large-diameter pipes. Determining the stability of the stratified flow regime requires the calculation of the liquid height, which can be obtained by writing the momentum balance equations for the gas and the liquid phases. At downward inclinations, transitions from stratified flow to other flow can occur when the gas velocity at which waves on the liquid surface are large enough to bridge the pipe and/or liquid droplets are sheared off from the wavy interface and deposited on the upper pipe wall, eventually developing into an annular film.

\subsection{Annular-Mist Flow}

The model is based on the assumption of a constant film thickness and accounts for the entrainment of the liquid in the gas core. Slip between the liquid droplets in the gas core and the gas phase is not accounted for. The transition from annular flow is based on two conditions. The first of the transitions is based on the observation that the minimum interfacial shear stress is associated with a change in the direction of the velocity profile in the film. When the velocity profile becomes negative stable annular flow cannot be maintained and the transition to intermittent flow occurs. This transition mechanism is only relevant during uphill flow. The second mechanism occurs when the supply of liquid in the film is sufficient to cause blockage of the gas core by bridging the pipe. This is said to take place when the in situ volume fraction of liquid exceeds one half of the value associated with the maximum volumetric packing density of uniformly sized gas bubbles (0.52).

\subsection{Bubble Flow}

When the liquid fraction in the slug is greater than 0.48 and the stratified, annular and dispersed bubble flow regimes have been eliminated, the flow will either be intermittent, froth or bubble flow. Bubble flow is encountered in steeply inclined pipes and is characterized by a continuous liquid phase containing a dispersed phase of mostly spherical gas bubbles. It can exist if the Taylor bubble velocity exceeds the bubble velocity and the angle of inclination is large enough to prevent migration of bubbles to the top wall of the pipe. The transition to bubble flow from intermittent flow occurs when the gas void fraction (during slug flow) drops below the critical value of 0.25 .

\subsection{Intermittent Flow}

The intermittent flow model includes the slug and elongated bubble flow patterns. It is characterized by alternating slugs of liquid trailed by long bubbles of gas. The liquid slug may contain dispersed bubbles and the gas bubbles have a liquid film below them. A transition from intermittent flow occurs when the liquid fraction in the slug exceeds the value associated with the maximum volumetric packing density of the dispersed bubbles. The same mechanism can occur at low liquid rates when sufficient liquid is not available for slug formation. The elongated bubble flow regime is defined as the portion of intermittent flow for which the liquid slug contains no dispersed bubbles of gas. The liquid volume fraction may be determined by writing an overall liquid mass balance over a slug-bubble unit.

\subsection{Froth Flow}

When none of the transition criteria listed above is met, the flow pattern is designated as "Froth" implying a transitional state between the other flow regimes. 


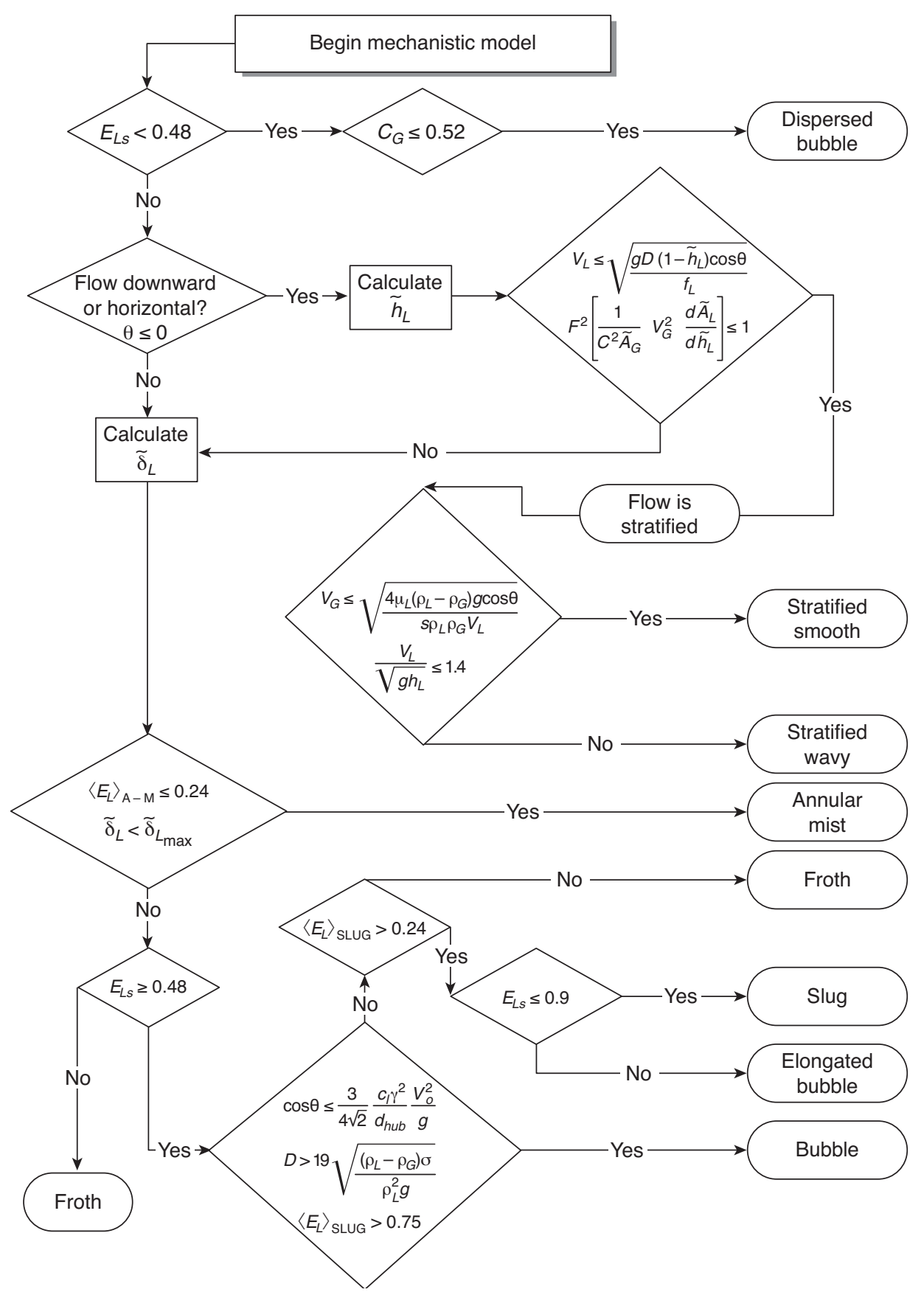

Figure 1

Flow pattern determination for Petalas and Aziz mechanistic model [12].

\section{THERMODYNAMIC DESCRIPTION OF THE FLUID}

Pressure gradient over a step length of the gas-lifted well depends on the local fluid properties including the phase densities, viscosities and inter-phase surface tension. The phase properties of the fluid can be obtained via a compositional treatment or a black-oil model approach.
The compositional treatment is based on a cubic equation of state calculation for the phase equilibrium of the fluid. Thus, given the temperature, pressure, composition and overall flow of the fluid, the phase densities, viscosities and inter-phase surface tension can be computed. However, in case of the black-oil thermodynamic description, the fluid properties are calculated from empirical correlations using merely the pressure values. 
Hydrocarbon properties together with those for water are then passed into a two-phase flow model to find the pressure drop along the gas-lifted well in a pressure traverse calculation procedure.

\section{BLACK-OIL MODEL}

In the three-phase black-oil model, two pseudo components namely oil and gas are used to describe the hydrocarbon fluid system. A third pseudo component is also used to describe the water. The pseudo components are usually defined as phases at standard conditions. For example, the gas (vapor) and oil (liquid) at surface conditions are labeled as the gas and oil pseudo components, respectively. In the generalized black-oil formulation, each hydrocarbon phase (gas and oil) at reservoir conditions can be made up of two pseudo components. One can associate a component with a master phase. In the standard black-oil model, only the gas component is allowed to dissolve in the oil phase. For a given reservoir temperature, the gas solubility is usually expressed as the gas-oil-ratio and a function of pressure. In addition to the solubility, the black-oil model employs the concept of formation volume factor, which is defined as the ratio of the fluid phase volume at reservoir conditions to standard conditions. Essentially, the black-oil approach employs a simple model to represent the PVT behavior of the fluids and ignores the mass transfer occurring between the water phase and the other two phases. In the black-oil model, the fluid properties can be supplied as functions of pressure and temperature via data tables or they can be calculated from built-in correlations. The built-in correlations for oil PVT properties should be tuned to match the data measured at bubble point, separator and reservoir conditions. The PVT behavior may be based on a number of experimentally measurable parameters such as the gas-oil ratio, the formation volume factors for oil, gas

TABLE 1

Physical properties correlations used for the black-oil model

\begin{tabular}{c|c}
\hline Parameter & Correlation \\
\hline Solution gas-oil ratio & Standing [13] \\
Oil formation volume factor & Frick [14] \\
Gas compressibility factor & Hall and Yarborough [15] \\
Oil compressibility & Vasquez and Beggs [16]) \\
Oil viscosity & Beggs and Robinson [17] \\
Gas viscosity & Lee et al. [18] \\
Water viscosity & Beal [19] \\
Oil density & Standing [13] \\
Oil-gas interfacial tension & Katz et al. [20] \\
Water-gas interfacial tension & Kaye and Laby [21] \\
\hline
\end{tabular}

and water. The basic correlations utilized to generate the physical properties for the black-oil model are given in Table 1 and were tuned to match the measured physical properties.

\section{COMPOSITIONAL MODEL}

Compositional model deals with a quite large number of components in which dependence of the PVT phase behavior on composition is modeled. The physical properties of a fluid depend on whether the fluid is present as a single phase or splits into several equilibrium phases. Flash calculation is therefore required to determine the number of equilibrium phases as well as their amounts and compositions. Here, Lapene et al. [9] free-water flash method is used based on Peng-Robinson equation of state. It assumes negligible solubility of hydrocarbon components in water-rich liquid phase and pure water for water phase. In this method, equilibrium state for each species in the three-phase mixture of vapor, hydrocarbon-rich liquid and water is expressed as following.

Physical and thermodynamic properties must be evaluated as a function of pressure, temperature and composition at each point. Component distribution among the various phases is determined by phase-equilibrium calculations. This requires the molar-balance constraint to be preserved, the chemical potentials of each component be the same for all phases, and the Gibbs free energy at constant temperature and pressure be minimized. These can be described for a mixture of hydrocarbon-water fluid having $N_{c}$ components as:

$$
f_{i}^{O}=f_{i}^{V}=f_{i}^{W}: i=1, N_{c}
$$

and using fugacity coefficients as:

$$
P \emptyset_{i}^{O} x_{i}^{o}=P \emptyset_{i}^{V} y_{i}=P \emptyset_{i}^{W} x_{i}^{W}: i=1, N_{c}
$$

The two equilibrium ratios are defined as:

$$
\begin{gathered}
K_{i}^{\mathrm{I}}=\frac{y_{i}}{x_{i}^{O}}=\frac{\emptyset_{i}^{O}}{\emptyset_{i}^{V}}: i=1, N_{c} \\
K_{i}^{\mathrm{II}}=\frac{y_{i}}{x_{i}^{W}}=\frac{\emptyset_{i}^{W}}{\emptyset_{i}^{V}}: i=1, N_{c}
\end{gathered}
$$

In a free-water system, water is distributed over the three phases while the rest of other components present only in vapor and hydrocarbon (non-aqueous) phases. This assumption reads:

$$
x_{i=w}^{W}=1 ; \quad x_{i \neq w}^{W}=0
$$

Thus, Equation (4) is simplified for the water component and takes the following form:

$$
y_{w}=K_{w}^{\mathrm{II}}
$$

and from Equation (3):

$$
x_{W}^{O}=\frac{K_{w}^{\mathrm{II}}}{K_{w}^{\mathrm{I}}}
$$


The component material balance for vapor/oil/water systems is:

$$
z_{i}=y_{i} V+x_{i}^{o} O+x_{i}^{W} W: i=1, N_{c}
$$

and the overall material balance equation is:

$$
V+O+W=1
$$

Using Equations (6) to (8) for the water component, an expression for the water fraction is obtained:

$$
W=\frac{z_{w}+V\left(x_{w}^{O}-y_{w}\right)-x_{w}^{O}}{1-x_{w}^{O}}
$$

For non-water components, Equation (8) can be written as following, using Equations (3) and (9):

$$
z_{i}=x_{i}^{O} K_{i}^{\mathrm{I}} V+x_{i}^{O}(1-V-W): i \neq w
$$

Finally, using Equation (10), expressions for mole fractions of component $i$ in hydrocarbon-rich liquid and vapor phases as functions of feed composition, equilibrium constants and vapor fraction are obtained from Equation (11):

$$
\begin{gathered}
x_{i}^{O}=\frac{z_{i}}{1+V\left(K_{i}^{\mathrm{I}}-1\right)-W} \\
=\frac{z_{i}}{1+V\left(K_{i}^{\mathrm{I}}-1+\frac{y_{w}-x_{w}^{O}}{1-x_{w}^{O}}\right)+\frac{x_{w}^{O}-z_{w}}{1-x_{w}^{O}}}: i \neq w \\
y_{i}=x_{i}^{O} K_{i}^{\mathrm{I}}: i \neq w
\end{gathered}
$$

When thermodynamic treatment of $c$ is described by a compositional model, the hydrocarbon-water fluid properties are computed from a phase equilibrium calculation. Moreover, the density of oil $\left(\rho_{O}\right)$, vapor $\left(\rho_{V}\right)$ and water $\left(\rho_{W}\right)$ are computed from the following relations:

$$
\begin{gathered}
\rho_{O}=\frac{M w_{O}}{v_{O}} \\
\rho_{V}=\frac{M w_{V}}{v_{V}} \\
\rho_{W}=\frac{M w_{W}}{v_{W}}
\end{gathered}
$$

where $M w$ and $v$ are the weight of one mole and the volume of one mole of each phase respectively. The molar weights of oil and vapor are found as follows:

$$
\begin{gathered}
M w_{O}=\sum_{i=1}^{N_{c}} x_{i}^{o} M w_{i} \\
M w_{V}=\sum_{i=1}^{N_{c}} y_{i} M w_{i}
\end{gathered}
$$

In compositional model, the oil and gas viscosities are found from the Lohrenz, Bray and Clark correlation, using the phase composition and molar volume in addition to component critical properties. Moreover, the water viscosity is calculated from Beal's correlation. The surface tension between oil and gas may be computed from the MacLeod-Sugden relation that requires component parachors in addition to the phase equilibrium calculation [22].

\section{RESULTS AND DISCUSSION}

An illustrative example based on a mature oil field was used to demonstrate the effect of different thermodynamic approaches on three-phase pressure drop calculation in a gas-lifted well with high water-cut. The reservoir characteristics and initial conditions are shown in Tables 2 and 3. The particular well considered in this study had a depth of $1800 \mathrm{~m}$ equipped with a gas-lift valve at $80 \mathrm{~m}$ above the sand face. The temperature of the wellbore was assumed to fall linearly from the reservoir temperature to that at the surface. The fluid from the well entered a common manifold and was directed to a train of three separators placed in series.

TABLE 2

Gas-lift process characteristics

\begin{tabular}{l|c}
\hline Areal extent of reservoir $\left(\mathrm{km}^{2}\right)$ & 10 \\
\hline Thickness $(\mathrm{m})$ & 60 \\
\hline Initial reservoir pressure (bar) & 170 \\
\hline Reservoir temperature (K) & 361 \\
\hline Porosity & 0.19 \\
\hline Permeability (md) & 200 \\
\hline Well depth (m) & 1800 \\
\hline Gas injection depth (m) & 1720 \\
\hline Average gas injection rate $(1000 \mathrm{scm} /$ day) & 243 \\
\hline Tubing diameter (m) & 0.121 \\
\hline Separator pressure (bar) & 11 \\
\hline Common manifold diameter $(\mathrm{m})$ & 0.5 \\
\hline Common manifold length $(\mathrm{m})$ & 500 \\
\hline
\end{tabular}

In order to study the composition variation through the gas-lifted well, calculations of three-phase pressure drop based on the black-oil model and compositional free-water flash model were compared. The pressure and temperature at the bottom-hole were taken as 170 bar and $360 \mathrm{~K}$ respectively. Pure methane was injected as a lifting gas at a rate of $56000 \mathrm{scm} /$ day.

Effect of water-cut on the pressure profile of the gas-lifted well is demonstrated in Figure 2. It shows the pressure of the well at different water-cut values obtained from the black-oil model. Figure 3 shows the profile using three-phase compositional model at the same condition. It is evident from Figure 2 that the pressure drop of the well is increased at high water-cut. The pressure drops below the value of surface 
TABLE 3

Composition and component properties of the reservoir fluid

\begin{tabular}{c|c|c|c|c|c|c}
\hline No. & Component & $\begin{array}{c}\text { Composition } \\
\text { (moles) }\end{array}$ & $\begin{array}{c}M_{w} \\
(\mathrm{~g} / \mathrm{mole})\end{array}$ & $\begin{array}{c}T_{c} \\
(\mathrm{~K})\end{array}$ & $\begin{array}{c}P_{c} \\
(\mathrm{bar})\end{array}$ & $\omega$ \\
\hline 1 & $\mathrm{CO}_{2}$ & 1.63 & 44.01 & 304.21 & 73.77 & 0.2250 \\
2 & $\mathrm{H}_{2} \mathrm{~S}$ & 0.17 & 34.08 & 373.60 & 90.08 & 0.0810 \\
3 & $\mathrm{~N}_{2}$ & 0.25 & 28.01 & 126.20 & 33.94 & 0.0400 \\
4 & $\mathrm{C}_{1}$ & 14.39 & 16.04 & 190.60 & 46.00 & 0.0115 \\
5 & $\mathrm{C}_{2}$ & 7.13 & 30.07 & 305.40 & 48.84 & 0.0908 \\
6 & $\mathrm{C}_{3}$ & 8.08 & 44.10 & 369.80 & 42.46 & 0.1454 \\
7 & $i-\mathrm{C}_{4}$ & 1.67 & 58.12 & 408.10 & 36.48 & 0.1760 \\
8 & $n-\mathrm{C}_{4}$ & 4.67 & 58.12 & 425.20 & 38.00 & 0.1928 \\
9 & $i-\mathrm{C}_{5}$ & 1.61 & 71.94 & 464.74 & 34.77 & 0.2235 \\
10 & $n-\mathrm{C}_{5}$ & 2.95 & 72.15 & 469.60 & 33.74 & 0.2273 \\
11 & $\mathrm{C}_{6}$ & 5.42 & 84.99 & 515.28 & 32.57 & 0.2637 \\
12 & $\mathrm{C}_{7}^{+}$ & 52.03 & 243.0 & 744.47 & 17.17 & 0.8561 \\
\hline
\end{tabular}

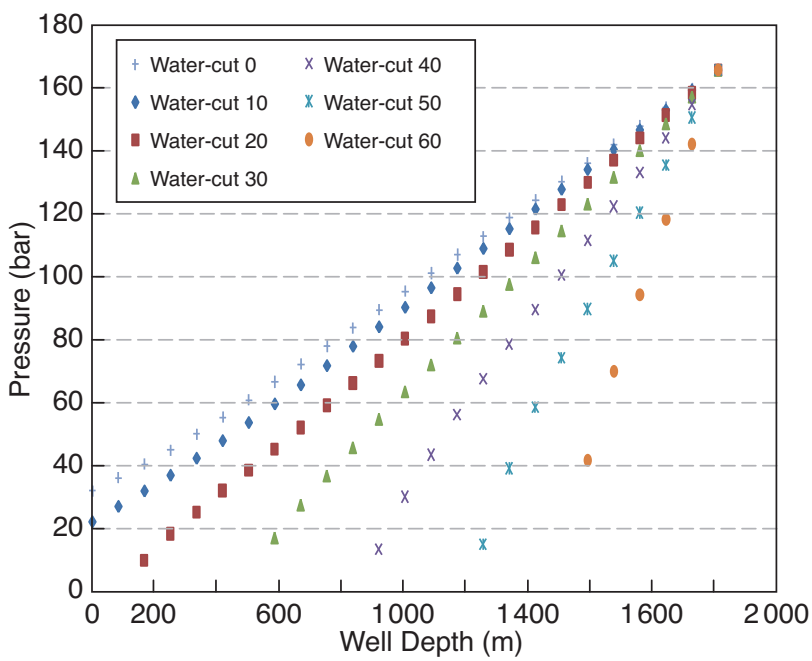

Figure 2

Pressure profile of the gas-lifted well predicted by threephase black-oil model at different water-cuts.

pressure causing the pressure drop calculations to stop in a section of the well.

Figure 4 compares the two sets of results obtained from black-oil model to those of compositional model. Water-cut values were 0,20 and 40\%. The comparison between phase superficial velocities and pressure profiles shows that more deviation between black-oil and compositional model encounter at higher water-cut values. The calculated pressure may drop below the surface separator pressure at water-cut 40 causing the pressure curve discontinuity.

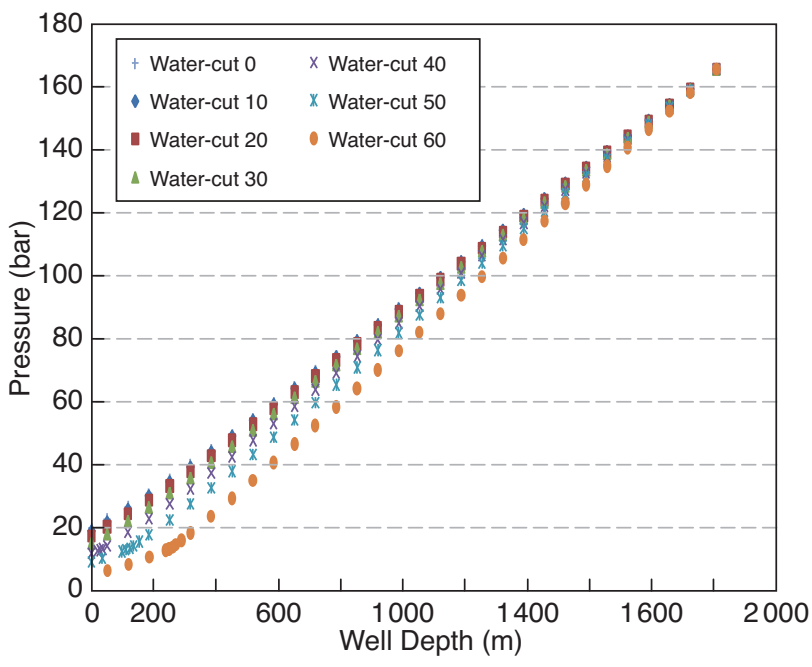

Figure 3

Pressure profile of the gas-lifted well predicted by the threephase compositional model at different water-cuts.

The ignoring or considering the solubility of the injection gas in the produced fluids of gas-lifted well is the major difference of black-oil and compositional approaches in modeling of fluid thermodynamic behavior. The black-oil model does not take into account solution of injected gas into the produced oil, so the gas appears as free gas beside the oil. By contrast, compositional model allows the injected gas to dissolve in the oil and equilibrium flash calculations determine the amount of the free gas. From Figure 4, as in black-oil model the injection gas is insoluble in the produced fluid, its flow rate and superficial velocity are greater than those in compositional approach. This point effects on the liquid and water superficial velocities. As the pressured drop and pressure profile in the well are calculated base on phase superficial velocities, the calculated pressure from black-oil and compositional models are significantly different.

In all curves of gas superficial velocities in Figure 4, there is one point that the slope of the superficial gas velocities is changed drastically. These points are related to the mixture state, changing from single liquid to vapor-liquid phase. The bubble pressures are 124.56,1 811.1 and 18210.7 bar for the fluid having 0,20 and 40\% water-cut respectively.

However, the amounts of solubility of water in hydrocarbon rich phases (liquid and vapor) are small but at a high value of water and oil flow rates in well, the water flow rates in hydrocarbon phases will be considerable. Figure 5 shows the flow rates of water in hydrocarbon phases at two water-cut values: 20 and $40 \%$. As expected, in higher water-cut values, more water enters the hydrocarbon phases and more deviation is arisen between black-oil and compositional approaches. 
a) Water-cut $=0 \%$
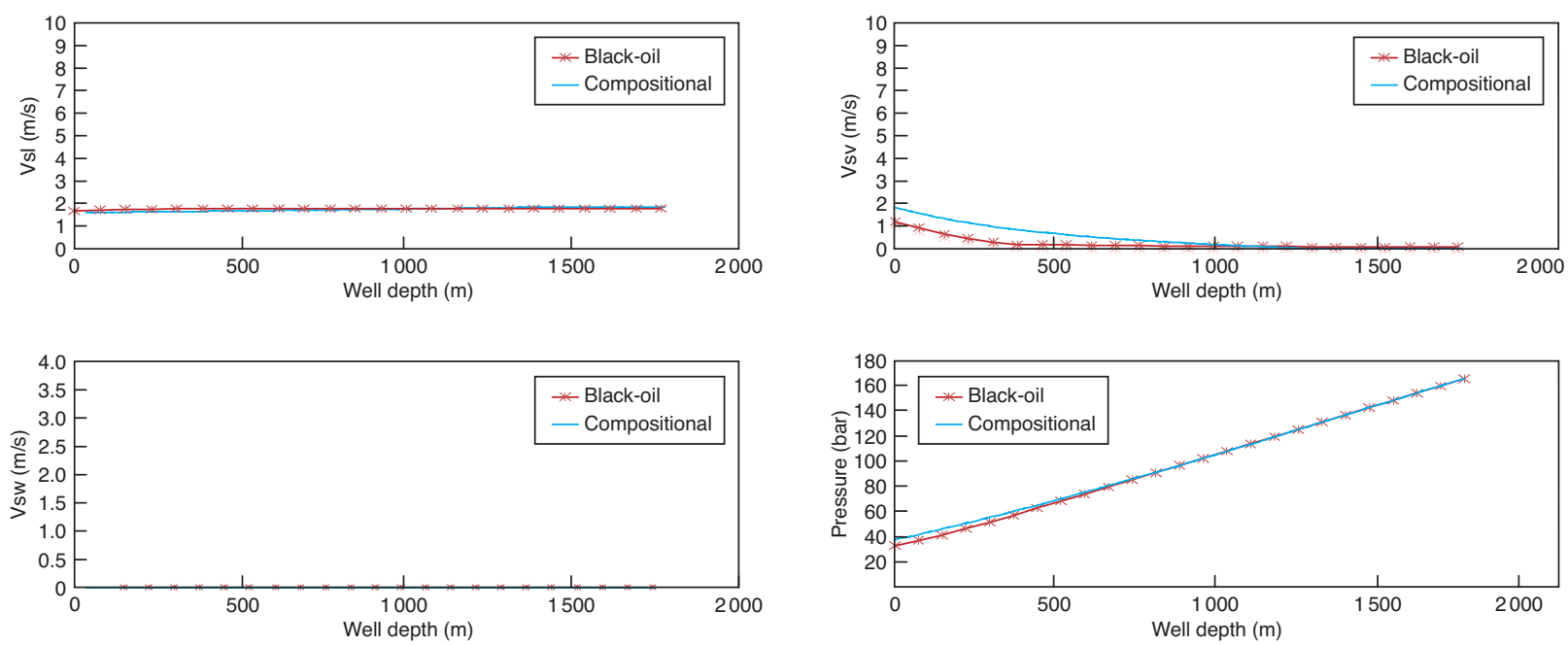

b) Water-cut $=20 \%$
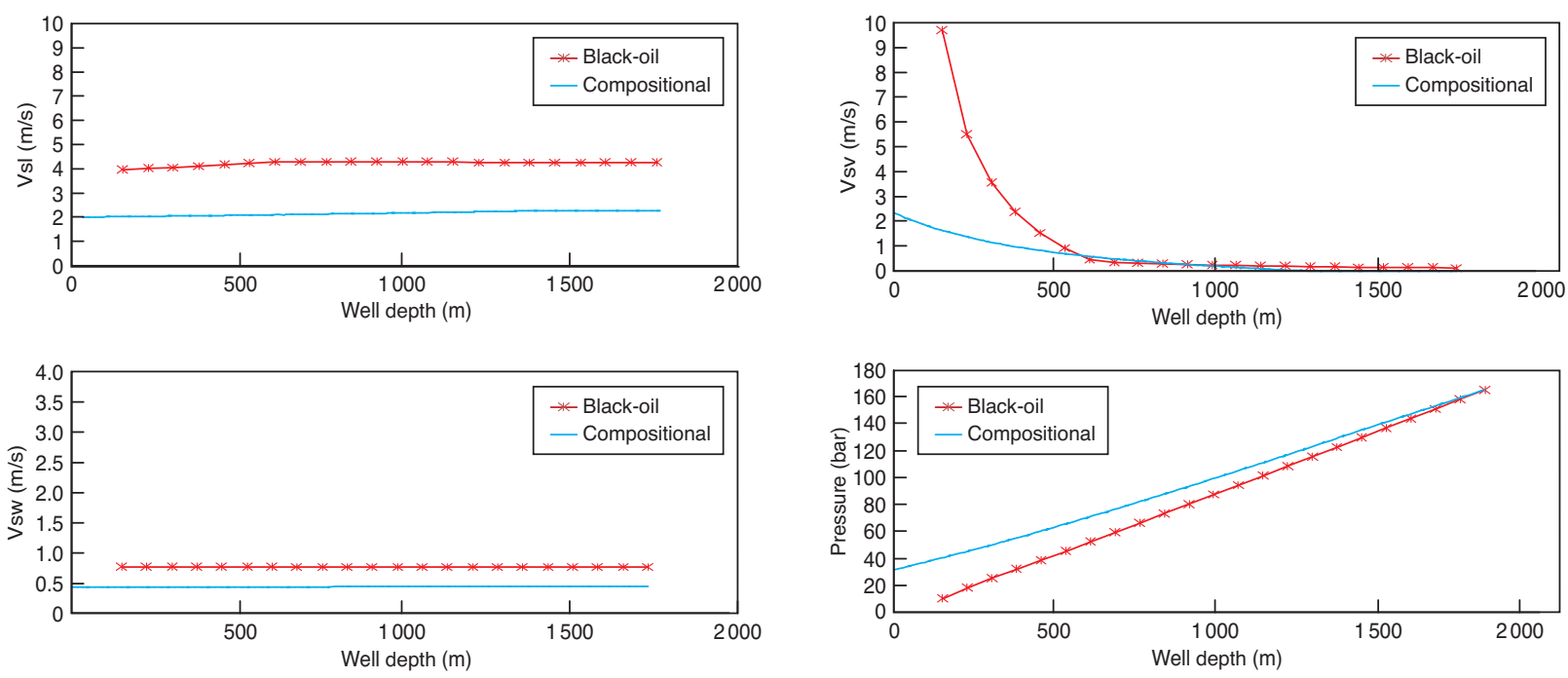

c) Water-cut $=40 \%$
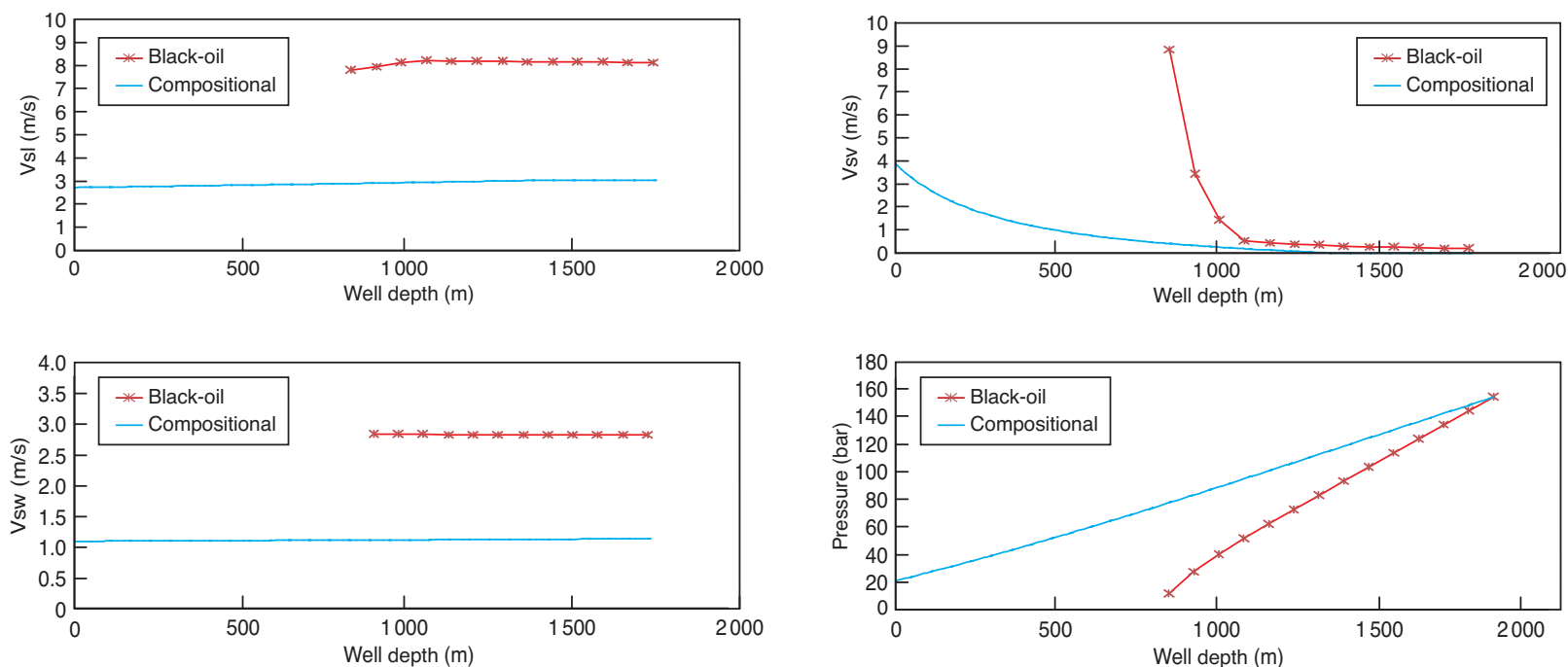

Figure 4

Variation of liquid/gas/water superficial velocities and pressure with well depth at different water-cuts. 

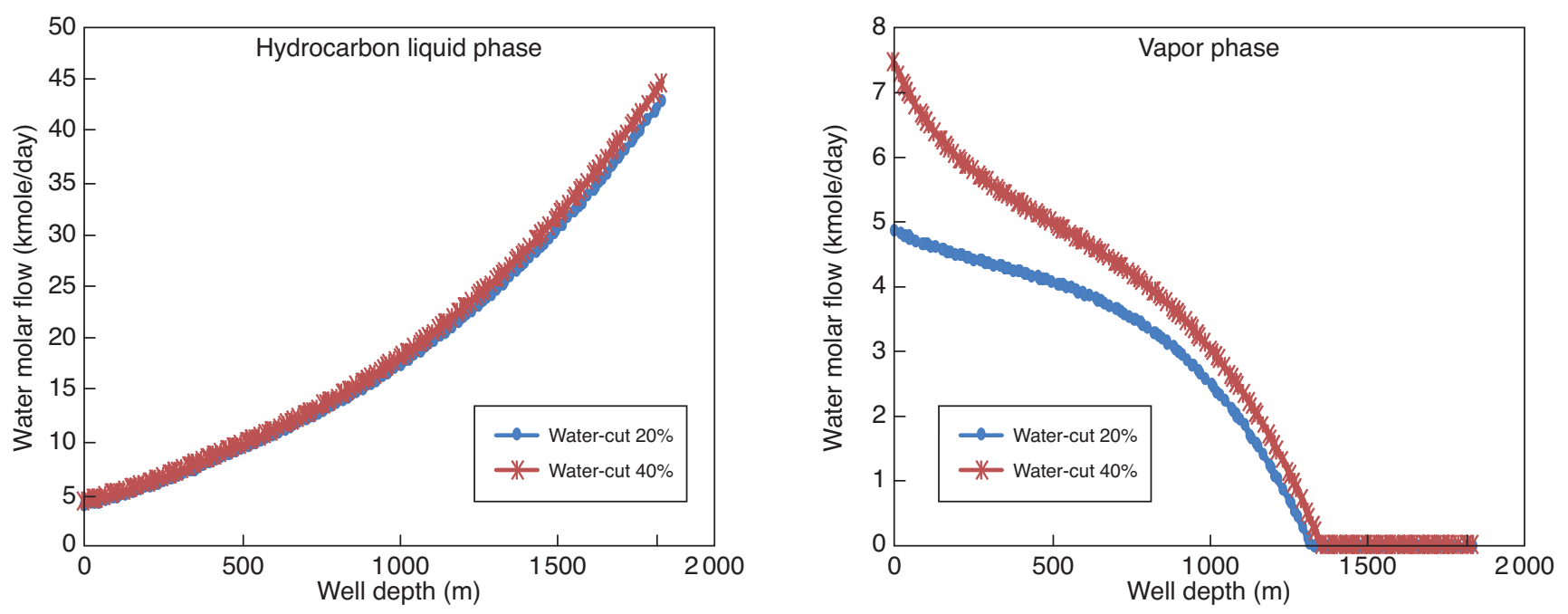

Figure 5

Variation of water molar flow rate in each hydrocarbon liquid and vapor phases with well depth at different water-cuts.

Results show that the three-phase black-oil model may provide a good approximation for modeling gas-lift process at initial production periods where the hydrocarbon fluid contain a low value of water. The difference with the black-oil model seems in the first instance not to great however, the difference plays an important role when calculation of the multi-phase flow in a gas-lift process having high water-cut values is required.

\section{CONCLUSIONS}

The continuous gas-lift technique is often employed as the reservoir pressure declines due to depletion or water-cut increase. A three-phase compositional model based on freewater flash method was developed to study the gas-lift process for an oilfield having a high water-cut. A case study with different water-cut values was considered to compare a three-phase black-oil model against the compositional model. It was shown that, the difference between black-oil modeling and compositional results would increase as the water-cut increases. Therefore, it is necessary to perform a three-phase multi-phase flash calculation to find the extent, physical property and superficial velocity of the phases in modeling a gas-lifted well with moderate and/or high water-cut.

\section{REFERENCES}

1 Takacs G. (2005) gas-lift Manual, PennWell Corp.

2 Guanren H. (1986) The Black Oil Model for a Heavy Oil Reservoir, SPE International Meeting on Petroleum Engineering, Beijing, China, 17-20 March, SPE Paper 14853.
3 Shi H., Holmes J.A., Diaz L.R., Durlofsky L.J., Aziz K. (2005) Drift-Flux Parameters for Three-Phase Steady-State Flow in Wellbores, 2004 SPE Annual Technical Conference and Exhibition, Houston, Texas, 26-29 Sept., SPE Paper 89836.

4 Cazarez-Candiaa O., Vasquez-Cruz M.A. (2005) Prediction of Pressure, Temperature and Velocity Distribution of Two-Phase Flow in Oil Wells, J. Petrol. Sci. Eng. 46, 195-208.

5 Hasan A.R., Kabir C.S., Sayarpour M. (2007) A Basic Approach to Wellbore Two-Phase Flow Modeling, 2007 SPE Annual Technical Conference and Exhibition, Anaheim, California, 11-14 Nov., SPE Paper 109868.

6 Peaceman D.W. (1977) Fundamentals of Numerical Reservoir Simulation, first edition, Elsevier Scientfic Publishing Company, Amsterdam-Oxford-New York.

7 Fadaei H., Quintard M., Debenest G., Renard G., Kamp A.M. (2008) How in Situ Combustion Process Works in a Fractured System: Two-dimensional, Core and Block Scale, Simulation International Thermal Operations and Heavy Oil Symposium, Calgary, Alberta, Canada, 20-23 Oct., SPE Paper 117645.

8 Akin S., Bagci S. (2001) A laboratory study of single-well steam-assisted gravity drainage process, J. Petrol. Sci. Eng. 32, 23-33.

9 Lapene A., Nichita D.V., Debenest G., Quintard M. (2010) Three-phase free-water flash calculations using a new Modified Rachford-Rice equation, Fluid Phase Equilib. 297, 121-128.

10 Varavei A., Sepehrnoori K. (2009) An EOS-based Compositional Thermal Reservoir Simulator, SPE Reservoir Simulation Symposium, The Wood-lands, Texas, 2-4 Feb., SPE Paper 119154.

11 Iranshahr A., Voskov D.V., Tchelepi H.A. (2009) Phase Equilibrium Computations are No Longer the Bottleneck in Thermal Compositional EoS Based Simulation, SPE Reservoir Simulation Symposium, The Woodlands, Texas, 2-4 Feb., SPE Paper 119166.

12 Petalas N., Aziz K. (1997) A Mechanistic Model for Stabilized Multiphase Flow in Pipes, A report for the members of Stanford Reservoir Simulation Industrial Affiliates and Stanford Project on the Productivity and Injectivity of Horizontal Wells, Petroleum Engineering, Stanford University. 
13 Standing M.B. (1981) Volumetric and Phase Behavior of Oil Field Hydrocarbon Systems, 9th ed., Millet the Printer Inc., Dallas, Society of Petroleum Engineers.

14 Frick T.C. (1962) Petroleum Production Handbook, Vol. 2, Millet the Printer Inc., Dallas, Society of Petroleum Engineers.

15 Hall K.R., Yarborough L. (1974) How to Solve Equation of State for Z-Factors, Oil Gas J., 72, 7, 86-88, Feb. 18th.

16 Vazquez M., Beggs H.D. (1980) Correlations for Fluid Physical Property Predictions, J. Petrol. Technol. June, 968-970.

17 Beggs H.D., Robinson J.R. (1975) Estimating the Viscosity of Crude Oil Systems, J. Petrol. Technol. Sept., 1140-1141.

18 Lee A.L., Gonzalez M.H., Eakin B.E. (1966) The Viscosity of Natural Gases, J. Petrol. Technol. Aug., 997-1000.
19 Beal C. (1946) The Viscosity of Air, Water, Natural Gas, Crude Oil and its Associated Gases at Oil-Field Temperatures and Pressures, Trans. AIME 165, 94-115.

20 Katz D.L., Monroe, R.R., Trainer R.P. (1943) Surface Tension of Crude Oils Containing Dissolved Gases, J. Petrol. Technol. Sept., 21.

21 Kaye G.W.C., Laby T.H. (1973) Tables of Physical and Chemical Constants, Longman Inc., New York.

22 Ahmed T. (2010) Reservoir Engineering Handbook, 4th ed., Gulf Publishing Company, Houston, Texas.

Final manuscript received in July 2012 Published online in March 2013 